\title{
A revolução da Gabriela: o ano de 1977 em Portugal"
}

\author{
Isabel Ferin Cunha**
}

\begin{abstract}
Resumo
Este trabalho apresenta os contextos da visionação, em 1977, da telenovela brasileira Gabriela, Cravo e Canela. Justifica-se a escolha do Corpus - dois diários (Diário de Notícias, Diário de Lisboa) e dois semanários (Expresso e $O$ Jornal) explicitando-se as metodologias utilizadas na análise de imprensa. Faz-se o levantamento da agenda da telenovela Gabriela, Cravo e Canela nos quatro jornais seleccionados, confrontando-a com outra agenda, mais lata, da expansão e divulgação da indústria cultural brasileira em Portugal. Considera-se que o êxito desta telenovela antecipa a emergência de uma nova sociedade e estilos de vida, bem como uma outra imagem da mulher, centrados em novos valores, no consumo e nos media.
\end{abstract}

Palavras-chave: Gênero, Análise dos Media, Telenovela Brasileira, Portugal, Estilos de Vida.

\footnotetext{
* Recebido para publicação em novembro de 2002, aceito em março de 2003. Publicado em português de Portugal.

** Instituto de Estudos Jornalísticos, Universidade de Coimbra.
}

cadernos pagu (21) 2003: pp.39-73. 
A revolução da Gabriela

Gabriela's Revolution: the Year of 1977 in Portugal

\begin{abstract}
This work describes the reception of the Brazilian telenovela Gabriela, Cravo e Canela in the year of 1977 in Portugal. The corpus is composed of two daily newspapers (Diário de Notícias, Diário de Lisboa) and two weekly papers (Expresso e O Jornal); The methods of analisys are presented. Afterwards the Agenda of the telenovela Gabriela... is identified in these newspapers and compared with the Agenda of Brasilian Cultural Industry in Portugal. The conclusion aims at a relation between the exhibition of the telenovela and the rise of a new society with new women's models and life styles.
\end{abstract}

Key Words: Gender, Media Analysis, Reception Studies, Brazilian Telenovelas, Life Styles. 
Isabel Ferin Cunha

\section{Introdução}

Em Portugal, o ano de 1977 inicia um período de transição, após os anos de revolução de 1974-76, que irá terminar, segundo Barreto $^{1}$, apenas com a entrada de Portugal na União Europeia (U.E.) em 1985. É um período em que a

crise política é quase permanente, pela instabilidade, por um alto grau de conflitualidade, pela "normalização" da democracia e do mercado, pelo gradual desfazer dos dispositivos constitucionais revolucionários e até pelas consequências de recessões e crises económicas externas. ${ }^{2}$

É o ano de vigência do I Governo Constitucional eleito nas primeiras eleições livres, em 1976, para a Assembleia e Presidência da Republica. O ano em que se formaliza o pedido de adesão de Portugal à U.E. e se inicia o percurso de "reunir" pedaços após a "revolução dominada" na perspectiva de Kenneth Maxwell. ${ }^{3}$

No que respeita aos direitos das mulheres, as alterações introduzidas na Constituição de 1976, vêm legitimar situações adquiridas consagrando o princípio de à "igualdade na vida, a igualdade na lei". Por outro lado, a magnitude dos problemas sociais a enfrentar no pós Revolução de Abril, como o direito à habitação, saúde e educação, diluem as reivindicações específicas dos poucos movimentos de mulheres. ${ }^{4}$

As grandes questões nacionais centram-se em temas como: a intervenção do FMI e as suas imposições (pacotes) económicas;

1 Barreto, A. (org.) A situação social em Portugal, 1960-1995. Lisboa, Instituto de Ciências Sociais, 1996.

2 ID., IB., p.39.

3 Maxwell, K. A construção da democracia em Portugal. Lisboa, Ed. Presença, 1999.

4 TAVARES, M. Movimentos de Mulheres em Portugal: décadas de 1970 e 1980. In: JOAQUIM, T. e GALHARDO, A. Novos olhares: passado e presente nos Estudos sobre as Mulheres em Portugal. Lisboa, Celta, 2003, pp.61-69. 
a legislação sobre a reforma agrária e a imprensa; as agitações no mundo do trabalho; as lutas partidárias e intrapartidárias (nomeadamente, do Partido Socialista e do Partido Popular Democrático/Partido Social Democrático contra o Partido Comunista); os movimentos separatistas dos Açores e da Madeira; as acções bombistas de extrema-direita e extrema-esquerda.

No contexto internacional há que ter em consideração a política americana de intervenção nas zonas consideradas "estratégicas" tendo como pano de fundo a partilha do mundo em duas áreas de influência, a americana e a soviética. A ter em conta, também, o percurso de normalização democrática em Espanha, o reforço de regimes ditatoriais na América Latina (com ênfase para a Argentina, o Brasil e o Chile), os conflitos na África Austral com especial relevância em Angola, Moçambique, África do Sul e antiga Rodésia, e o caso da invasão do Timor-Leste pela Indonésia.

No Espaço Lusófono a imprensa focaliza, preferencialmente, Angola, Brasil, Moçambique e Timor. Angola domina grande número de secções internacionais com as seguintes temáticas: papel dos cubanos na guerra contra a UNITA, as pretensões separatistas da UNITA, o movimento de Nito Alves $e$ os "fraccionistas"; a participação de portugueses no movimento "fraccionista" e a normalização das relações diplomáticas com Angola. O Brasil é tratado na perspectiva do recrudescimento da repressão política; do papel da Igreja na denúncia da violação dos direitos humanos (prisão e tortura de activistas políticos e estudantes); a sucessão do general Geisel; visitas de personalidades da oposição a Portugal entre elas Miguel Arraes e Fernando Henrique Cardoso. Moçambique surge no momento da invasão $e$ ataques dos sul-africanos e aquando da expulsão de portugueses e indianos. Timor é motivo de notícia quando é invadido pela Indonésia e anexado como $27^{\mathrm{a}}$ província.

Este contexto nacional $e$ internacional reflecte-se na imprensa portuguesa espelhando, contudo, as orientações e os percursos pós 25 de Abril de cada órgão de comunicação, 
Isabel Ferin Cunha

independentemente de se encontrarem, em grande parte, nacionalizados ou intervencionados pelo Estado em consequência da nacionalização da banca e dos seguros.

Como afirma Joaquim Vieira,

Não houve praticamente jornalista ou órgão de informação que, nos dois anos de brasa que se seguiram (74-75), não se enfeudasse a um partido, a uma corrente, a uma ideologia. Era como se os jornalistas portugueses, habituados a uma prática rigorosamente vigiada, não concebessem a profissão sem um patrão político-ideológico a quem devessem vassalagem. Confundiu-se informação com proselitismo. ${ }^{5}$

Convém notar que após os acontecimentos do 11 de Março de 1975, o Estado português detém a RTP (Rádio Televisão Portuguesa) e a RDP (Rádio Difusão Portuguesa); o Diário de Notícias, o Século (e todo o seu grupo), o Diário Popular, a Capital, o Jornal de Notícias, O Jornal, Record e o Rádio Clube Português. O Estado intervém ainda (dizia-se, na época, "jornais intervencionados") no Diário de Lisboa, Comércio do Porto e Primeiro de Janeiro. ${ }^{6}$

A esta altura encontra-se na mão de particulares a Rádio Renascença (devolvida à Igreja Católica em 1976) e semanários de referência como o Expresso (fundado em 1973, por Pinto Balsemão), O Jornale Tempo, ambos fundados em 1975.

A imprensa dirigida às mulheres, designada imprensa feminina, constava de alguns títulos com tiragens na ordem dos milhares, que se dividiam em revistas de divulgação geral $e$ revistas especializadas. Nas primeiras encontravam-se revistas de qualidade desigual como a pioneira Mulher: modas e bordados -

5 VIEIRA, J. A emancipação do jornalismo português:1945-1995. In: Portugal 451995 nas Artes, nas Letras e nas Ideias. Lisboa, Centro Nacional de Cultura, 1998, p.276.

${ }^{6}$ Cfr: Mascarenhas, O. Nacionalizações 25 anos depois. Diário de Notícias, Lisboa, 14/03/00, p.4. 
considerada uma revista de qualidade e promotora de debates emancipatórios - e as tradicionais Donas de Casa e Mulher d'Hoje. Quanto às revistas especializadas identificam-se as revistas de fotonovelas, as que incidiam sobre a programação da rádio $e$ da televisão (uma estação pública) e as de divulgação de produtos para o lar e as mulheres. ${ }^{7}$

Quanto à televisão ela foi, durante trinta e cinco anos (de 1957 a 1992), um monopólio do Estado. Esta situação provocou, por um lado, um isolamento da televisão frente a outros media, $e$ por outro, a certeza da intervenção financeira e reguladora de um patrão complacente. ${ }^{8}$ A televisão pública portuguesa participou, assim, do período revolucionário ao lado de quem esteve $e$ alternou no poder. $^{9}$ Com uma programação circunscrita a dois períodos - hora do almoço e fim de tarde das $18 \mathrm{~h}$ às $23 \mathrm{~h}$ - incorporou nos anos revolucionários a doutrina "desenvolvimentista" da formação e educação das massas, com programas de "esclarecimento" político, debates e complementação escolar.

Em 1977, ainda sem a Lei da Televisão em vigor, o avolumar dos problemas orçamentais (provocados em parte pela fuga à taxa obrigatória) das crises laborais partidarizadas, levam a uma reestruturação da televisão e à reformulação de programas.

É nesta conjuntura que surgem dois programas, $A$ visita da Cornélia (um concurso-reallity show) e a telenovela Gabriela, Cravo e Canela, que alterarão o percurso da televisão em Portugal ao mesmo tempo que anteciparão e simbolizarão a emergência de uma nova sociedade e estilos de vida centrados no consumo e nos media.

7 Benavente, A. A libertação da mulher e a imprensa feminina. Diário de Lisboa, Lisboa, 26 de Julho de 1997, pp.10-11.

8 Paquete de Oliveira, J.M. Comunicação Social, Verso e Reverso do País Real e Imaginário. In: Portugal Hoje. Oeiras, Instituto Nacional de Administração, 1995, pp.369-389.

925 anos inesquecíveis: os pontos altos da televisão. Expresso, n 1848 , Lisboa, 1998. 
Isabel Ferin Cunha

\section{O corpus}

Como caracterizar ou como tentar uma caracterização de cada um destes jornais diários e semanários em 1977?

Com esta finalidade procedemos ao levantamento do ano de 1977 em cada um dos jornais tendo em conta os seguintes indicadores: formatos, tiragens, público-alvo, secções, títulos $e$ leads, conteúdos e tratamento de conteúdos.

Observou-se com especial atenção as primeiras páginas, secções, suplementos, cadernos e revistas sem esquecer o nosso objectivo primeiro: o ano de 1977 na perspectiva da Transição e da telenovela Gabriela, Cravo e Canela. A utilização destes critérios permite, então, avançar uma caracterização dos quatro jornais que passamos a descrever.

O Diário de Notícias (DN), em formato broadsheet e uma tiragem de cerca de 94000 números diários, tem um público-alvo de classes médias urbanas e rurais. Está organizado em secções (nem sempre bem delimitadas) e apresenta semanalmente cadernos de análise política, nacional e internacional, bem como de análise económica, financeira e cultural. Os seus títulos e leads denunciam uma linguagem contida, evitando os jargões políticos da época, com parágrafos longos e títulos descritivos. Poder-se-á avançar que há uma orientação preferencial pela "cultura erudita" e pelo debate cosmopolita que ela proporciona. Talvez daí a resistência em incluir uma secção "televisão" ou mesmo uma rubrica sobre televisão na secção "Artes e Espectáculos" e a vinculação constante da telenovela Gabriela, Cravo e Canela à obra de Jorge Amado.

O Diário de Lisboa (DL), um vespertino de formato tabloide com uma tiragem de cerca de 46000 exemplares, apresenta secções definidas e suplementos com matérias cedidas por jornais como Le Monde, Prensa Latina, Interpresse e Novosti. Publica, também, aos fins de semana um suplemento, tipo agenda cultural, denominado Sete, ponto, Sete. O seu público-alvo são os "trabalhadores" (indústria e serviços). Os títulos e os leads surgem 
vinculados ao jargão marxista da época, independentemente da clareza da linguagem e da concisão dos parágrafos. A secção "Espectáculos" de Jorge Leitão Ramos apresenta os inúmeros filmes, nunca exibidos até então em Portugal; e a secção "Canal da Crítica" de Mário Castrim aborda toda a programação da RTP enfatizando e politizando ao longo de seis meses os conteúdos de Gabriela, Cravo e Canela. Por outro lado, o DL vai abrir espaços para a divulgação de estudos sobre a "cultura de massa" ao publicar textos sobre o impacto da literatura feminina ${ }^{10}$, assim como promover novas formas de viver a língua $e$ a cultura lusófona. ${ }^{11}$

O semanário $O$ Jornal em formato tabloide, com uma tiragem de cerca de 60000 exemplares, tem como público-alvo as classes médias assalariadas, com escolarização média e superior, principalmente funcionários públicos. Utiliza uma linguagem directa, próxima da descrição visual, transitando do jargão da esquerda à linguagem coloquial. $O$ fotojornalismo ocupa um grande espaço e dá a este semanário um aspecto "moderno". Apresenta secções bem definidas graficamente e uma diagramação geométrica. "Artes e Espectáculos", "Rádio", "Televisão", "Cinema", "Música" são secções constantes $e$ assinadas por colaboradores permanentes (no caso da televisão, Francisco Mata) assim como a famosa secção do "Tempo Livre" assinada pela Guidinha (o escritor Luís Sttau Monteiro), onde as referências a Gabriela serão intermediadas pela crítica sóciopolítica e cultural.

\footnotetext{
${ }^{10}$ Benavente, A. A libertação da mulher e a imprensa feminina. Diário de Lisboa, Lisboa, 26 de Julho de 1997, pp.10-11; e A libertação da mulher e a imprensa feminina II. Diário de Lisboa, Lisboa, 18 de Agosto, 1977, p.3.

${ }^{11}$ Cfr.: Prof. Barradas de Carvalho categórico: Independência nacional está no rumo atlântico não na integração europeia. Diário de Lisboa, Lisboa, 13 de Junho de 1977, pp.12-13; Mário de Andrade ao DL: a estrutura das línguas africanas vai domesticar a língua portuguesa. Diário de Lisboa, Lisboa, 30 de Junho de 1977, pp.10-11.
} 
Isabel Ferin Cunha

O semanário Expresso, de formato broadsheat e cerca de 70000 exemplares vendidos, dirige-se, neste período, a um público de empresários e profissionais liberais de tendência liberaldemocrática. A relevância concedida às políticas económicas europeias e ocidentais demonstram as preocupações dos seus leitores. Apresenta secções e rubricas bem definidas, uma linguagem não vinculada ao jargão da época e um conjunto notável de comentadores e opinion makers originários da área política. Na secção "Comunicação Social" é constante a discussão e reflexão sobre os rumos da imprensa, rádio e televisão. $\mathrm{Na}$ rubrica televisão, a crítica surge assinada por Augusto de Carvalho, enquanto que Kafarnaum, os cartoons de António ${ }^{12}$ politizam e tematizam a telenovela e na Revista se incita a "estudos mais aprofundados" sobre o fenómeno Gabriela em Portugal. ${ }^{13}$

\section{Agenda, telenovela $e$ indústrias culturais}

Enunciar o princípio das teorias do Agenda-Setting - "as pessoas têm tendência para incluir ou excluir dos seus próprios conhecimentos aquilo que os mass-media incluem ou excluem do seu próprio conteúdo"14 - é relembrar a omnipresença e centralidade dos media na construção da realidade, a discussão sobre a existência de efeitos cumulativos e a capacidade dos públicos negociarem sentidos ao apropriarem-se de conteúdos diversos. ${ }^{15}$ Apesar destas teorias tentarem, preferencialmente, explicar os efeitos de agendamento na televisão, dentro de uma

${ }^{12}$ ANTÔNIO. Kafarnaum: Gabriela: resumo dos episódios de férias. Expresso Revista, Lisboa, 27 de Agosto de 1977, p.15; e Kafarnaum: Dona Flor e seus dois maridos. Expresso Revista, Lisboa, 1 de Outubro, 1977, p.19.

${ }^{13}$ Gabriela. Expresso Revista. Lisboa, 16 de Novembro de 1977, p.14.

${ }^{14}$ apud Wolf, M. Teorias da Comunicação. Lisboa, Presença, 1992, p.128.

${ }^{15}$ MARTIN-BARBERO, J. Dos meios às mediaçóes: comunicação, cultura $e$ hegemonia. Rio de Janeiro, Ed. UFRJ, 1997. 
lógica produtivista da notícia, a imprensa não está imune a este processo.

No ano de 1977 a imprensa de referência portuguesa mantém, ainda, - considerados os contextos históricos e os percursos particulares - um elevado sentido de "serviço público" que se traduz, frequentemente, na partidarização do jornal e, por conseguinte, na politização da notícia. ${ }^{16}$

A estas constantes não fogem os dois diários (DN e DL) e os dois semanários (Expresso e O Jornal) que elegemos como corpus de análise, o que permite ter como hipótese que cada um dos jornais tende a reflectir determinadas tendências latentes na sociedade portuguesa, inclusivamente, quando agenda a telenovela Gabriela. A cada jornal, a cada grupo social (ou grupos sociais) que o jornal tende a representar corresponderia, então, um discurso ${ }^{17}$ que os seus membros - neste caso jornalistas $e$ críticos - interiorizaram como sendo "o seu discurso", mas que na verdade corresponderia a um discurso do seu grupo (ou grupos) de pertença.

As notícias sobre a telenovela Gabriela, Cravo e Canela apresentam, ainda, uma outra particularidade, a de tenderem a inverter a estrutura narrativa do discurso da imprensa caracterizada pela apresentação do evento/acontecimento seguida da interpretação feita pelo jornalista. No caso das notícias sobre esta telenovela é a aproximação, feita pelos jornalistas, aos factos sócio-políticos do quotidiano, que tenderá a tornar as "estórias" da telenovela uma história dos anos revolucionários ${ }^{18} e$ principalmente a História do ano de $1977 .{ }^{19}$

${ }^{16}$ VIEIRA, J. A emancipação do jornalismo português... Op. cit., pp.276-278.

${ }^{17}$ VAN DIJK, T.A. Discourse and cognition in society. In: CROWLY, D. et alii. Communication Theory Today. London, Polity Press, 1994, pp.107-126.

${ }^{18}$ CASTRIM, M. Canal da Crítica: Gabriela outra vez ela. Diário de Lisboa, Lisboa, 5 de Novembro de 1977, p.11; Dionísıo, M. Ideias e opiniões: Crónica de Verão. O Jornal, Lisboa, 6 de Agosto de 1977, p.18.

${ }^{19}$ ID. Canal da Crítica: Gabriela, mas... aviso ao público: a crónica de hoje fala de política. Diário de Lisboa, Lisboa, 28 de Outubro de 1977; GuidiNHA. Tempo 
Isabel Ferin Cunha

O processo de agendamento obedece a três grandes fases; Fase de Lançamento $e$ apresentação da telenovela, personagens da trama, actores e possíveis impactos na língua e cultura portuguesa (durante o mês de Maio e Junho); Fase de Tematização forte, que corresponde à selecção e interpretação do argumento, papel das personagens, contextos históricos e correspondente politização da telenovela em Portugal (abrange os meses de Julho a Outubro); Fase de Encerramento (Outubro e Novembro) centrada na promoção dos actores, na identificação da telenovela como um produto de uma indústria cultural, e de conteúdos, e nos efeitos e formas de recepção da telenovela.

A campanha de lançamento da telenovela Gabriela, nos quatro jornais seleccionados, obedece a timings publicitários, com um cartaz de meia página ${ }^{20}$ anunciando a chegada da telenovela e vinculando-a, na diagramação do cartaz, a Jorge Amado, uma referência para grande número de portugueses. A mesma campanha envolveu press releases ${ }^{21}$ e uma apresentação pública - num Hotel de Lisboa, feita pelo humorista Raúl Solnado, dos actores e personagens principais - patrocinada pela TV Globo, acompanhada por um espectáculo de MPB (Música Popular Brasileira) encabeçado por Vinicius de Morais.

Para assinalar a estreia deste folhetim a TV Globo oferece na segunda-feira no Hotel Ritz, em colaboração com a nossa televisão um cocktail e um espectáculo que será transmitido em directo, a partir das 21.40. Denominada "Noite Brasileira" esta transmissão inclui uma entrevista com Jorge Amado (que a rede Globo já traz gravada) a presentação feita por Raul Solnado, do primeiro episódio

Livre: Os tonicos e os ramiros da Graça. O Jornal, Lisboa, 29 de Julho de 1977, p.13.

${ }^{20}$ Por exemplo, Diário de Notícias, Lisboa, 16 de Maio de 1977, p.4; Expresso, Lisboa, 21 de Maio de 1977, p.5.

${ }^{21}$ Gabriela, Cravo e Canela: seis meses de folhetins diários. O Jornal, Lisboa, 1 de Abril de 1977, p.26. 
A revolução da Gabriela

de "Gabriela, Cravo e Canela" e o "show" em que actuarão os artistas brasileiros Vinicius de Morais, Toquinho, Maria Creuza e um quarteto instrumental. Parte do espectáculo será transmitido, também em directo, para o Brasil, via satélite. ${ }^{22}$

É visível, pela campanha de lançamento que o agendamento da telenovela Gabriela deverá, ainda, ser enquadrado numa Agenda maior que integra as indústrias culturais e de conteúdos brasileiras.

São produtos de grande impacto e consumo: a música popular brasileira, a indústria livreira, o teatro e o cinema. No momento em que se assiste ao lançamento do primeiro capítulo da telenovela, 16 de Maio, as rádios e a televisão mantinham programas regulares de divulgação da $\mathrm{MPB}^{23}$, os romances de Jorge Amado eram best-sellers na feira do livro ${ }^{24}$ e nas livrarias. ${ }^{25}$ Enquanto encenações de Boal (Barraca conta Tiradentes ${ }^{26}$ ) e uma peça de Dias Gomes ( $O$ Santo Inquérito ${ }^{27}$ ) eram exibidas nos teatros da capital com notável êxito de bilheteira. No mesmo período o cinema brasileiro chega a Portugal, quer através de festivais mais selectivos, como o da Figueira da $\mathrm{Foz}^{28}$, quer através

${ }^{22}$ De Gabriela à Vaca Cornélia na nova programação da RTP. Diário de Notícias, Lisboa, 14 de Maio de 1977, p.11.

${ }^{23} \mathrm{O}$ programa Tropicalia, por exemplo, às sextas-feiras às 19.30 , feito por correspondentes da RTP no Brasil.

${ }^{24}$ Entre surpresas e Barracas de "Artesanato" Gabriela manda na Feira (do livro). Diário de Lisboa, Lisboa, 20 de Maio de 1977, p.4.

${ }^{25}$ Cfr: Livros mais vendidos. Expresso Revista, Lisboa, 28 de Maio a 26 de Novembro de 1977.

${ }^{26}$ FEIO, L. Barraca conta Tiradentes: o êxito de uma companhia... O Jornal, Lisboa, 6 de Maio de 1977, p.25.

${ }^{27}$ Teatro de Campolide estréia "Santo Inquérito". O Jornal, Lisboa, 16 de Setembro de 1977, p.25.

${ }^{28}$ Cfr: VI Festival de Cinema da Figueira da Foz: Da Gabriela aos filmes de Leste. Diário de Notícias, Lisboa, 22 de Setembro de 1977, p.8. São referidos os 
Isabel Ferin Cunha

do grande circuito comercial (Dona Flor e seus dois maridos ${ }^{29}$, $O$ Casamento de Arnaldo Jabor e Xica da Silva de Cácá Diegues ${ }^{30}$ ).

Lisboa teve oportunidade, na última semana, de apreciar três filmes brasileiros. Para um cinema que nunca nos visita é um pequeno acontecimento, quase uma lança em África. Pode ser que a promoção seja feita, daqui para o futuro, por via indirecta, isto é, quando a TV vier a exibir a anunciada Série "Gabriela, Cravo e Canela" romance da Baía na obra do mesmo nome do grande Jorge Amado. Talvez nessa altura o público se interesse pelo cinema que fala a mesma língua e espelha um povo diferente... ${ }^{31}$

A relação entre os diversos produtos da indústria cultural $e$ de conteúdos com a telenovela é estabelecida constantemente, de diversas formas $e$ a diferentes níveis: entre a literatura $e$ a telenovela, entre o teatro, os actores e a telenovela, entre a MPB e a telenovela, assim como entre o cinema, os actores $e$ a telenovela.

A obra de Dias Gomes, "O Santo Inquérito", recentemente estreada em Lisboa, foi classificada ontem, pelo autor, como "essencialmente polémica". Simultaneamente era anunciada a possível apresentação, em Portugal da sua telenovela "O Bem amado"... ${ }^{32}$

seguintes filmes: A lenda de Ubirajara de André Luís de Oliveira; Barra Pesada de Reginaldo Farias; Tenda dos Milagres de Nelson Pereira dos Santos.

${ }^{29}$ RAmOS, J. L. Crítica do cinema: "Dona Flor e seus dois maridos" de Nuno Barreto. Diário de Lisboa, Lisboa, 17 de Novembro de 1977, p.13.

${ }^{30}$ ID. Crítica de Cinema: "Xica da Silva" de Carlos Diegues, "O casamento" de Arnaldo Jabor. Diário de Lisboa, Lisboa, 3 de Maio de 1977, p.14.

${ }^{31}$ PereirA, J.V. Cinema "Hora do Brasil". O Jornal, Lisboa, 6 de Maio de 1977, p.24.

${ }^{32}$ Segundo o seu autor: Santo Inquérito, uma obra essencialmente polémica. Diário de Notícias, Lisboa, 20 de Setembro de 1977, p.6. 
A revolução da Gabriela

Ao longo da fase de tematização, a tratar separadamente, os jornais portugueses vão, paulatinamente, reconhecendo a telenovela como sendo "um formato singular do género ficcional na categoria entretenimento da comunicação televisiva latino americana". ${ }^{33} \mathrm{O}$ conhecimento da telenovela, como um género ficcional autónomo - não é por acaso ${ }^{34}$ que a telenovela é referida, alternadamente, como um romance traduzido para a televisão, um folhetim, uma fotonovela e uma série - faz-se ao longo dos cerca de sete meses de visionamento ao mesmo tempo que são divulgadas e identificadas as suas lógicas de produção, distribuição e consumo, quer pela televisão, quer pelos jornais.

Televisão: "Gabriela" ainda, mas por detrás dos bastidores como foi concebida e produzida a telenovela da TV Globo. Reportagens e entrevistas, nomeadamente com Jorge Amado, técnicos e intérpretes de "Gabriela". 35

O agendamento, promove, como estratégia de divulgação da telenovela e em interacção com o público o seu sistema de estrelas, o starsystem da TV Globo. ${ }^{36}$ Este fenómeno, de dimensões completamente novas em Portugal, próprio da cultura de massas, faz desaparecer as fronteiras entre o real $e$ o imaginário $^{37}$ e cria aquilo que os jornais chamaram a Gabrielomania $^{38}$ a que não estão imunes os políticos mais empenhados.

\footnotetext{
${ }^{33}$ MARques DE Melo, J. A Legitimação da Telenovela pela Mídia Impressa Brasileira, 1964-1997. 1999, mimeo, 42p.

${ }^{34}$ ORTIZ, R., Borelli, S.H.S. e RAmOS, J.M.O. Telenovela: História e produção. $2^{\text {a }}$ edição, São Paulo, Brasiliense, 1991.

${ }^{35}$ Cfr: Expresso Revista, Lisboa, 12 de Novembro de 1977, p.14R.

${ }^{36}$ Lopez-PumAjero, T. Aproximacion a la telenovela. Madrid, Catedra, 1987, p.118.

${ }^{37}$ Marques de Melo, J. A Legitimação da Telenovela... Op. cit., p.10.

${ }^{38}$ Gabrielomania instala-se em Portugal: as mil "leituras" de um folhetim. $O$ Jornal, Lisboa, 21 de Outubro de 1977, pp.13-16.
} 
Isabel Ferin Cunha

Que o primeiro ministro português confesse a um jornalista do Sunday Times que goste de ver a Gabriela - ainda vá! Agora que o secretário-geral do PCP, esse modelo de rigidez de costumes, de não alienação de hábitos, de ocupação politicamente empenhada dos tempos livres, não perca um episódio da Gabriela é tema para as maiores especulações jornalísticas. E no entanto, Álvaro Cunhal chegou aos estúdios do Lumiar na passada terça-feira, para participar no programa "Mosaico" atrasado não por ter estado num comício ou sessão de esclarecimento, não por se ter prolongado numa sessão do Secretariado da Comissão Política do Comité Central - mas apenas e tão somente por ter ficado a ver "Gabriela"..."

A telenovela Gabriela produz, ainda, em Portugal, e num contexto sócio-político muito específico, um fenómeno de coesão e consenso social em função da interactividade que promove com o seu público - interpelando-o a partir da sua unidade básica de audiência, a família, no seu quotidiano - proporcionando um factor de mediação cultural e política entre os diversos grupos sociais. ${ }^{40}$

Sabendo-se que, em 1977, o número de aparelhos de televisão por mil habitantes rondava os $150^{41}$ e que era prática corrente, nas aldeias, vilas e bairros, assistir-se à telenovela nos cafés, associações de bairro, associações de moradores ou sedes de outras associações cooperativas, pode-se imaginar o "efeito" de interactividade criado pelo simples facto de fruição conjunta da exibição.

...A Gabriela já lá ia e só ela realiza o milagre de juntar toda a gente, à mesma hora (incluindo os que consideram o PS o partido mais esquerdista deste mundo e do outro...), em

\footnotetext{
${ }^{39}$ Atrasado por causa da Gabriela. Expresso Revista, Lisboa, 1 de Outubro de 1977, p.10R

${ }^{40}$ Martin-Barbero, J. Dos meios às mediaçóes ... Op. cit., pp.291-303.

${ }^{41}$ Barreto, A. (org.) A situação social em Portugal... Op. cit., p.146.
} 
A revolução da Gabriela

frente do televisor e, pelos vistos, por mais que isso nos espante, com sentimentos semelhantes... ${ }^{42}$

Mais ainda, a telenovela identificada na literatura internacional como um produto da cultura de massa consumido, predominantemente, por mulheres ${ }^{43}$ surge em Portugal como um produto de consumo direccionado, preferencialmente, para o género masculino. Este facto explica-se, não só pela apropriação de sentidos realizada pelos jornalistas e críticos, reflectindo a arena política quotidiana enfrentada por políticos e homens politizados, onde a participação da mulher ronda os $5 \%,{ }^{44}$ mas também pelo facto de a visualização da televisão ser então um acto desfrutado $e$ controlado, predominantemente, pelos homens. Para esta situação contribui: o diminuto número de aparelhos de televisão; a actividade masculina rotineira de "ir ao café" à noite assistir à televisão (as mulheres ficam a arrumar a cozinha $e$ a deitar os filhos) e conversar com os vizinhos; a disponibilidade para ver televisão que os homens apresentam nesse horário, no caso do lar possuir um aparelho, em função das rotinas domésticas serem cumpridas tradicionalmente pelas mulheres.

Assim, não é de espantar que a luta de uma mulher pela sua liberdade seja cotejada com a luta de um povo pela sua liberdade:

A luta de uma simples mulher por abrir a sua janela [Glorinha] para a rua está cheia de uma grande verdade pessoal, e daí a sua capacidade de nos comover; mas ultrapassa essa verdade para ganhar o símbolo de um povo

${ }^{42}$ DionísIO, M. Ideias e opiniões: Crónica de Verão. O Jornal, Lisboa, 26 de Agosto de 1977, p.18.

${ }^{43}$ Morley, D. Television, Audiences and Cultural Studies. London, Routledge, 1992; LIVINGSTONE, S. Making Sense of Television. London, Routledge, 1998.

${ }^{44}$ TAVARES, M. Movimentos de Mulheres em Portugal... Op. cit., p.62. 
Isabel Ferin Cunha

que deseja defender o seu direito às janelas abertas, e daí a sua capacidade de captar a nossa adesão inteligente. ${ }^{45}$

No entanto, uma das poucas mulheres lideres de opinião, Isabel da Nóbrega, refere que "as meninas" da telenovela, sejam elas do "Bataclã" ou "das famílias abastadas", travam todas a mesma luta: "a luta pela sua emancipação, para serem aceites do jeito que são e não como a sociedade quer que sejam". ${ }^{4}$

Neste contexto, inaugurando práticas de marketing publicitário próprias de uma sociedade fundada num mercado concorrencial, a Pepsi ${ }^{47}$ - um dos refrigerantes proibidos até então e que simboliza, tal como a Coca-Cola, a entrada dos portugueses na sociedade de consumo $e$ a adopção de novos estilos de vida patrocina as viagens dos actores principais a Lisboa. A euforia que provoca estas visitas, sobretudo das actrizes, está reflectida nas primeiras páginas dos jornais seleccionados, para espanto dos actores convidados.

A popularidade da "Gabriela" no nosso país é um facto indesmentível. A chegada de "Malvina" e "Tonico Bastos" ontem de manhã, ao aeroporto de Lisboa, foi mais que elucidativo; desde os funcionários ali em serviço suspendendo a actividade, até às manifestações das largas centenas de pessoas que, dentro e fora do edifício, se comprimiam para ver mais de perto as conhecidas personagens da obra de Jorge Amado... ${ }^{48}$

${ }^{45}$ CASTRIM, M. Canal da Crítica: A Janela de Glorinha. Diário de Lisboa, Lisboa, 27 de Outubro de 1977, p.13.

${ }^{46}$ NóBREGA, I. Gabriela II. Diário de Lisboa, Lisboa, 6 de Setembro de 1977, p.3.

${ }^{47}$ A entrada em Portugal da Coca-Cola e da Pepsi-Cola não foi pacífica e só aconteceu neste ano. Cfr: Coca-Cola: uma autorização política desencadeia a "guerra económica". O Jornal, Lisboa, 28 de Janeiro de 1977, p.18; Show Pepsi. O Jornal, Lisboa, 4 de Novembro de 1977, p.40; A prodigiosa história da CocaCola. Expresso Revista, Lisboa, 14 de Maio de 1977, p.7R.

${ }^{48}$ Malvina e Tonico em Lisboa. Diário de Notícias, Lisboa, 3 de Novembro de $1977,1^{a}$ página com fotografia. 
Na Fase de Encerramento e tendo em consideração as particularidades da imprensa, internas e externas, é importante mencionar a polémica sobre o número de capítulos que teria, originariamente, a telenovela (seriam 160 ou seriam 130 capítulos?). Esta polémica tratada por alguns jornais num tom conspiratório denuncia, de certa forma, exemplarmente, a orientação político-partidária da redacção do jornal. $\mathrm{Na}$ interpretação de alguns jornalistas, a supressão dos últimos capítulos, visaria suavizar o carácter de denúncia política e social presente na telenovela, para outros tratava-se de mais um lapso no funcionamento, sempre deficiente, da televisão estatal, para outros ainda, um outro final feito pela Globo e enviado para Portugal.

Toda esta polémica é enunciada na $1^{a}$ página do Diário de Lisboa no dia em que será exibido o último capítulo da Gabriela:

Os telespectadores portugueses não verão 30 dos 160 episódios que constituem o popular folhetim "Gabriela", cuja transmissão a RTP hoje conclui. Com efeito, e segundo informação colhida pelo "DL" directamente do Brasil, a já célebre telenovela tem mais 30 episódios dos que a TV portuguesa transmitiu. Em contacto com a administração da RTP, fomos informados de que tal facto deve-se à TV Globo, que terá enviado apenas os episódios que a nossa televisão tem transmitido, adiantando ainda a hipótese de a congénere brasileira o ter feito em termos de comercialização para o exterior. Sobre o facto de a RTP ter anunciado, no início das transmissões, que iriam ser exibidos 160 episódios, fomos informados ter-se tratado de "lapso". De qualquer modo é muito estranho que a "Gabriela" fosse exibida na integra num Brasil com um regime ditatorial e seja exibido truncado no "democrático" Portugal. ${ }^{49}$

${ }^{49}$ Tiraram 30 episódios à "Gabriela". Diário de Lisboa, Lisboa, 16 de Novembro de $1977,1^{a}$ página. 
Isabel Ferin Cunha

Outros jornais, como $O$ Jornal e o Expresso ecoaram, também esta polémica, apesar de enfatizarem uma, ou outra, destas perspectivas.

\title{
A tematização da telenovela
}

\begin{abstract}
Wolf define tematização como
um procedimento informativo que se insere na hipótese do agenda-setting, dela representando uma modalidade particular: tematizar um problema significa, de facto, colocá-lo na ordem do dia da atenção do público, dar-lhe relevo adequado, salientar a sua centralidade e o seu significado em relação ao fluxo da informação nãotematizada..$^{50}$
\end{abstract}

No contexto do agendamento da Telenovela entendemos que a tematização se dá no momento em que se seleccionam determinados aspectos, em detrimento de outros. Este procedimento permite passar para além do acontecimento inicial a telenovela Gabriela, Cravo e Canela - e chamar a atenção para determinadas acções, atributos e objectos, inserindo-os, simultaneamente, em novos quadros interpretativos associados a outros acontecimentos e/ou fenómenos.

Neste processo de construção da realidade não se pode desprezar a presença da agenda dos diversos media, nomeadamente, a agenda fornecida pela TV Globo (diversas vezes referida), a da televisão portuguesa, pautada pela calendarização de um produto de impacto $e$, finalmente, a agenda de cada um dos jornais analisados.

O público (incluindo os jornalistas e os críticos) tenderá a apropriar-se do acontecimento telenovela em função das suas expectativas e referências mais prementes: os contextos sociais, económicos e políticos do Portugal pós revolução do 25 de Abril.

${ }^{50}$ Wolf, M. Teorias da Comunicação. Lisboa, Presença, 1992, p.144. 
Não admira, portanto, que as tematizações fortes se façam em torno da questão da língua e da literatura (questão de identidade no fim do Império colonial), da política (em função do período de grande conflitualidade vivida quotidianamente), dos actores e das personagens (espanto frente ao universo dos media portador de mitologias e utopias desconhecidas) e, por último, sobre os efeitos e a recepção da telenovela (necessidade de identificar apropriações de sentidos).

A selecção do tema língua e literatura obedece, inicialmente, à necessidade de justificar a exibição da telenovela, um produto em português e de qualidade literária. Contudo a questão da influência dos falares brasileiros no português de Portugal colocase de imediato quer como uma contaminação, um perigo, quer como um enriquecimento linguístico para os portugueses.

...A RTP acertou, desta vez, e é agradável ouvir uma obra na língua de Ilhéus, que amplia a nossa, matizando-a de palavras e consoantes sonoras desconhecidas da maioria dos portugueses. Uma língua que entra nas nossas casas de família, na intimidade dos lares, escapando-se à régua $e$ compasso dos gramáticos, filólogos e demais técnicos, e se está nas tintas para os dicionários... ${ }^{51}$

Se a questão da língua não é unânime, a escolha e o tratamento da obra literária recolhem aplausos gerais sugerindose, com frequência a necessidade de transpor ou traduzir, como é dito, para a televisão grandes obras da literatura clássica portuguesa. Por outro lado, o produto Gabriela, apresentando outros falares da língua e outras vivências da cultura em português revela a existência de um Espaço Lusófono a potenciar. Esta constatação está explícita, entre muitas outras, na seguinte afirmação de Mário de Carvalho no Expresso:

${ }^{51}$ Carvalho, A. Gabriela, tempo primeiro. Expresso Revista, Lisboa, 4 de Junho de 1977, p.7R. 
Isabel Ferin Cunha

...Perguntamo-nos, porém, quando é que a RTP terá coragem de apresentar obras da nossa terra, telenovelandoas. Estamos a pensar por exemplo, nos Maias de Eça de Queirós, actuais como nunca, nos Lusíadas e tantas outras. Quando se resolve a ir para África para nos mostrar o mundo que a língua portuguesa aprofundou. Quando é que neste capítulo a televisão se resolve descobrir Portugal para a revelar aos Portugueses... ${ }^{52}$

A relação entre as linguagens de ficção, a televisiva $e$ a literária, são, igualmente, evidenciadas ao mesmo tempo que se enfatiza o papel que esta telenovela teve nas vendas do romance de Jorge Amado conseguindo que obras de ficção, pela primeira vez no pós 25 de Abril, superassem em vendas os livros políticos.

Muitos telespectadores se precipitaram para a leitura do romance de Jorge Amado. Assim Gabriela, Cravo e Canela subiu aos primeiros lugares de venda, primeira, grande vitória da ficção nos três primeiros depois de Abril, marcados por um frenético interesse pelos livros de política... O êxito deve-se, sem dúvida, à projecção que à obra veio trazer a televisão. O que prova quanto a televisão podia ser útil à expansão da literatura em lugar de ser um elemento inimigo dela, como geralmente é. Os telespectadores atraídos ao livro por intermédio da televisão devem ter sentido a diferença, devem ficar com a impressão de que não há nenhuma relação entre a telenovela $e$ o romance....Quanto às grandes diferenças entre as duas obras (tão grandes que na realidade as tornam quase independentes uma da outra), há que atender às diferenças de linguagem, a televisual $e$ a literatura... ${ }^{53}$

${ }^{52}$ CARVAlHo, A. Gabriela, tempo primeiro. Op. cit, p.7R.

${ }^{53}$ CASTRIM, M. Canal da Crítica: Malvina entre Nós. Diário de Lisboa, Lisboa, 21 de Outubro de 1977, p.17. 
O tema política é o que envolve maior número de sub-temas. A política portuguesa é lida, relida, discutida, escrita e reescrita, humoristicamente glosada através da Gabriela, suas personagens, cenários e acções. É-lhe atribuída, assim como à televisão, o poder de educar ou deseducar, principalmente, num país com uma grande percentagem de analfabetos e tradicionalmente afastado das práticas políticas. Por exemplo, numa comparação entre a telenovela e o telejornal, Mário Castrim, crítico do DL, chama a atenção para o papel educador da primeira - e por extensão do audiovisualismo - apesar, de iniciar o artigo referindo a sua qualidade de produto industrial consumido por grandes audiências.

...Essa importância (a da telenovela) reside principalmente no facto de nos mostrar como tudo é material político, ou seja como a política utiliza como instrumentos factores que parecem nada ter com a política. O peso da emissão da Gabriela consistiu, não em dizer isto, mas em mostrar isto, em dar a ver isto. Por aqui se poderá avaliar da força do audiovisualismo num país com cerca de 40 por cento de analfabetos e uma grande percentagem de indivíduos durante anos $e$ anos afastados da prática política....Peço aos leitores que meditem se as notícias e reportagens chinfrins dos telejornais não servirão para preencher um lugar, para que a audiência não pense no que acontece, de essencial, neste país e que não aparece no Telejornal... ${ }^{54}$

Os sub-temas mais tratados na tematização política - e não será por acaso que o são nos jornais considerados mais politicamente empenhados - relacionam-se mais directamente com as vivências portuguesas do pós revolução 25 de Abril e com o período de transição para uma normalidade democrática. $\mathrm{O}$ agendamento da telenovela passa pela selecção e tratamento

${ }^{54}$ CASTRIM, M. Canal da Crítica: Gabriela, mas... aviso ao público: a crónica de hoje fala de política. Diário de Lisboa, Lisboa, 28 de Outubro de 1977, p.13. 
Isabel Ferin Cunha

dos conflitos resultantes das arbitrariedades ditatoriais, pela descrição das lutas e dos sofrimentos decorrentes da repressão indiscriminada, pelo papel da imprensa na denúncia das prepotências dos poderosos.

..."Ilhéus" não é uma terra estranha para muitos portugueses, "coronéis" também não. A luta pela queda da "ordem estabelecida", "a dos coronéis", com todo o caciquismo, repressão, machismo, etc... ${ }^{55}$

Um outro sub-tema tratado com relevância pelos jornalistas e críticos é a luta pela dignidade e liberdade, onde sobressaem os comentários politizados das "estórias" das mulheres, sejam elas filhas ou mulheres de intendente ou coronéis, ou, ainda, mulheres por conta de poderosos.

A politização da telenovela faz-se, muitas vezes, entremeando a ficção política com situações políticas concretas, neste caso a do Brasil:

...Vieram o "coronel" Jesuíno e seus capangas. Vieram, rasgaram o papel da sua própria lei, invadiram a casa de Glória e trancaram-lhe a janela, isto é: cegaram-na. Conheço alguém que fez o mesmo, tirem Glória e ponham povo brasileiro, tirem "coronel" Jesuíno e ponham general Geisel. A este sujeito chamam em todo o mundo assassino... Assassino chamou Glória a Geisel, perdão! A Jesuíno. ${ }^{56}$

O humor politizado constitui, ainda, um outro sub-tema a referir. São importantes os cartooms de António [Antunes] no jornal Expresso, as críticas irónicas da Guidinha [Luís Sttau

${ }^{55}$ F.M. Jorge Amado a Stefanini: "O seu Tonico é melhor que o meu..." Diário de Lisboa, Lisboa, 4 de Novembro de 1977, p.3.

${ }^{56}$ CASTRIM, M. Por quanto tempo, Glorinha, terás tua janela fechada? Diário de Lisboa, Lisboa, 27 de Outubro de 1977, p.15. 
Monteiro] no O Jornale as bandas desenhadas da agenda cultural de espectáculos, Sete ponto Sete, do Diário de Lisboa.

Este humor politizado - e, digamos, reciclado para fins comerciais - é, igualmente, recorrente na publicidade de diversas empresas e produtos. Por exemplo, no Expresso, uma loja de máquinas e artigos domésticos anuncia assim os seus produtos: Maria Machadão em São Bento [local onde se encontra a Assembleia da República]:

A fim de desfazer por completo a desconfiança dos coronéis sobre a sua fortuna, que permitiu o célebre empréstimo ao Dr. Mundinho para o jornal da oposição, esteve na DINAMICA [loja] a comprar mobília e uma máquina de lavar a prestações a famosa proprietária do Bataclan...

Aberto até às 20 horas, Dinâmica, Rua de S. Bento, 53 a 57, Lisboa. ${ }^{57}$

A tematização dos actores e suas personagens, as suas visitas, ou possíveis visitas constituem um outro foco denunciador do fenómeno inédito, da indústria cultural e de audiências, em que se tornou a telenovela entre nós. O agendamento privilegia tanto a dimensão ética e social da personagem - evocadas muitas vezes através da obra de Jorge Amado (por exemplo, Glorinha, o coronel Ramiro Bastos, Mundinho, etc.) - como a informação descritiva, tentando confrontar actor/personagem. São frequentemente contrapostas às personalidades dos actores com as características das suas personagens, por exemplo Elisabeth Savalla versus Malvina, Fulvio Stefanini versus Tonico Bastos, Nívea Maria versus Jerusa. Aquando das visitas ressalta, também, através das descrições dos jornalistas, muitas vezes, nas primeiras páginas, o espanto ou estupefacção - mútua por razões diversas perante a realidade actor.

${ }^{57}$ Expresso Revista, Lisboa, 12 de Novembro de 1977, p.14R. 
Neste aspecto poder-se-á dizer que esta tematização inaugura aquilo que Marques de $\mathrm{Melo}^{58}$ refere como "as relações de legitimação entre a imprensa e a televisão, criando uma intertextualidade, um dialogo de conteúdos, uma parceria discursiva" e abrindo espaços para novos produtos jornalísticos e mediáticos (revistas especializadas em telenovelas, programas televisivos de divulgação, etc.).

A tematização dos efeitos e da recepção, fazendo-se sentir desde o início no que se refere às questões da língua e literatura, evolui no final da telenovela para dois grandes sub-temas: os efeitos pós-Gabriela na programação da televisão portuguesa provocados pelas novas exigências do público; as diversas leituras da telenovela e subsequente necessidade de estudos mais aprofundados.

No primeiro sub-tema sublinhe-se que a inserção da telenovela no horário nobre fez parte de um processo de reestruturação da $\mathrm{RTP}^{59} \mathrm{O}$ sucesso alcançado, reconhecido unanimemente, promove novos acordos para a compra de telenovelas, enquadradas, mais uma vez, num outro processo de reestruturação que inclui a repetição da Gabriela à hora do almoço.

A Gabriela despede-se amanhã dos telespectadores. O epilogo daquela que foi a emissão de mais audiência neste país, que manteve "suspensos" meses a fio, milhões de portugueses, abre sem dúvida um novo capítulo na programação da nossa televisão. Constatado o êxito de Gabriela, uma equipa de responsáveis da RTP, deslocou-se ao Brasil e visionou mais de uma vintena de telenovelas produzidas pela TV Globo... Podemos adiantar, ainda, que

\footnotetext{
${ }^{58}$ Marques de Melo, J. A Legitimação da Telenovela... Op. cit., p.10.

${ }^{59}$ Nova programação da RTP já segunda-feira. Diário de Lisboa. Lisboa, 14 de Maio de 1977, p.6.
} 
A revolução da Gabriela

a RTP pensa reatar a emissão da hora do almoço incluindo nesse período uma telenovela. ${ }^{60}$

O reconhecimento deste êxito, como promotor da fidelização de grandes audiências ${ }^{61}$ através da "receita "telejornaltelenovela brasileira, faz a direcção da RTP (tendo como director José Niza) incluir, de imediato, um sucedâneo, nas suas grelhas de programação.

O Casarão vai ocupar o lugar de Gabriela: $O$ Casarão, de Lauro César Moniz, que foi grande êxito da TV Globo, vai ser - a partir de Janeiro de 1978 - o substituto da telenovela Gabriela. ${ }^{62}$

A opção pela telenovela brasileira como estratégia de fidelizar audiências não é pacífica, não só por se temer uma demasiada influência dos falares e vivências culturais brasileiras como por se considerar que à televisão pública, paga com impostos públicos, compete a divulgação da cultura feita em Portugal e por portugueses.

Numa entrevista feita ao director da RTP, José Niza, a jornalista de $O$ Jornal, pergunta se o Brasil não se terá transformado "numa fonte de inspiração da televisão portuguesa?" A esta pergunta o director da RTP responde:

...tenho a impressão que talvez não haja no mundo quem ofereça uma gama de produções provenientes de países tão diversos, como o Brasil, EUA, Canadá, França, Espanha,

${ }^{60}$ Não há êxito que sempre dure... Cornélia infantil no princípio do ano; Gabriela acaba na esperança de mais. Diário de Notícias, Lisboa, 15 de Novembro de 1977, $1^{a}$ página.

${ }^{61}$ Ferin-CunHA, I. As Agendas da telenovela brasileira em Portugal. In: SOPCOM Sociedade Portuguesa de ComuniCAÇÃo. As Ciências da Comunicação na Viragem do Século. Lisboa, Vega, 2002, pp.579-587.

${ }^{62}$ Nova programação da RTP: $O$ Casarão vai ocupar o lugar de Gabriela. $O$ Jornal, Lisboa, 16 de Dezembro de 1977, p.8. 
Isabel Ferin Cunha

Itália; RDA, Alemanha, Grã-Bretanha, Checoslováquia, Polónia, Rússia, Japão... Daí que não se possa falar em "inspiração brasileira", já que o leque é vasto. Não há nenhuma espécie de privilégio em relação ao Brasil a não ser este: tendo em conta o número de analfabetos que ainda existem em Portugal e até mesmo as crianças, o factor língua é importante, mesmo com toda aquela musicalidade que os brasileiros the dão... ${ }^{63}$

No último mês da exibição da Gabriela, os jornais em geral $e$ os semanários, em particular, promovem uma série de entrevistas e inquéritos tentando identificar a opinião pública e a apropriação de sentidos realizada tanto por personalidades públicas como pelo público em geral.

Neste esforço para compreender o impacto público da telenovela sobressai o semanário $O$ Jornal que realiza inquéritos a algumas dezenas de pessoas (figuras públicas e gente anónima) - e os apresenta em 4 páginas. ${ }^{64}$ Do leque de notáveis inquiridos encontram-se jornalistas e políticos conhecidos - apesar de alguns se recusarem alegando "não terem visto episódios suficientes para emitirem uma opinião..." - e entre estes últimos, Otelo Saraiva de Carvalho, Salgado Zenha (PS), Nandim de Carvalho (PSD), Ribeiro e Castro (CDS), Vítor Dias (PCP).

Neste trabalho, não assinado, os jornalistas reconhecem que cada indivíduo tende a apropriar-se dos sentidos da telenovela e a negociar as mensagens veiculadas em função do seu estrato cultural, das suas experiências de vida e da sua faixa etária.

...É evidente que a perspectiva e a argúcia de cada telespectador varia consoante as possibilidades que a vida lhes deu. Queremos dizer que, nessa visão, se colocam

${ }^{63}$ SoEIRO, E. Entrevista com José Niza: estamos preocupados em relação à continuidade da exibição de "Marco". O Jornal, Lisboa, 8 de Novembro de 1977, p.15.

${ }^{64}$ Inquérito: "Gabrielomania" instala-se em Portugal: as mil "leituras" de um folhetim. O Jornal, Lisboa, 21 de Outubro de 1977, pp.13-16. 
A revolução da Gabriela

questões (importantes) relacionadas com a cultura, e porque não ? - com a idade... ${ }^{65}$

No entanto, os mesmos jornalistas reconhecem que os inquiridos tendem a salientar determinadas temáticas como: semelhança entre a história da telenovela baseada no romance de Jorge Amado e a realidade portuguesa, passada e/ou presente; luta pela emancipação feminina; qualidade técnica da produção $e$ excelência dos actores.

As referências à semelhança entre a telenovela $e$ a realidade portuguesa são atribuídas, pelos jornalistas, quer a políticos (Otelo Saraiva de Carvalho, Salgado Zenha e Vitor Dias) quer a populares. Por exemplo, Otelo Saraiva de Carvalho enfatiza que "a Gabriela deve ser vista com o objectivo de dela retirar os ensinamentos políticos especialmente aqueles que se referem à denúncia das prepotências e da corrupção do Poder" ${ }^{16}$, enquanto um estudante-trabalhador considera que a telenovela prende a atenção porque "há nela uma semelhança com a situação de fascismo que vivemos em Portugal durante quase meio século". Uma opinião um pouco diferente, tem, segundo o jornal, uma senhora sexagenária:

$\mathrm{Na}$ verdade o folhetim parece-se um bocado com aquilo que existia em Portugal antes do 25 de Abril... é verdade que as coisas não estavam nada bem no tempo do Salazar e do Marcelo... [mas acha que] o coronel Ramiro Bastos é uma péssima criatura, sem princípios, sem moral e muito desonesto [enquanto] o Salazar não era bem assim. Lá tinha as suas ideias, não se pode dizer que fosse simpático, mas parece-me que não era má pessoa de todo, embora não tinha sido muito bom para o povo tal como o coronel Ramiro Bastos...

${ }^{65}$ Inquérito: "Gabrielomania" instalou-se em Portugal: as mil "leituras" de um folhetim. O Jornal, Lisboa, 21 de Outubro de 1977, p.13.

${ }^{66}$ ID., IB., p.14. 
Isabel Ferin Cunha

Já o deputado do PCP entrevistado considera que, à volta da Gabriela,

muitas e variadas questões podem, sem dúvida, ser utilmente debatidas em função da própria realidade nacional $e$ de candentes problemas da sociedade portuguesa mas discorda que o País esteja paralisado, imobilizado ou de cócoras, perante Gabriela.

A qualidade técnica e a excelência dos actores é, preferencialmente, referida pelos jornalistas e profissionais de teatro que enaltecem a produção, cenários, trilha sonora $e$ capacidade de interpretação dos actores. Distinguem, com veemência, o produto de massas, telenovela, da obra literária de Jorge Amado, considerando que os dois têm linguagens distintas determinadas por exigências dos seus públicos distintos.

A telenovela Gabriela é muito mais telenovela do que Gabriela. E é mais "tele" do que novela. E faço "qú-és-tão" de dizer quem é "telexcelente"... ${ }^{67}$ (Frase de Carlos Pinhão, jornalista, acentuando a pronúncia brasileira)

O jornalista da RDP, Brandão Lucas, faz uma síntese interpretativa do fenómeno Gabriela atribuindo-o a um sentimento que parece assumir "um carácter de desencanto $e$ frustração" decorrente de promessas do 25 de Abril não concretizadas e nostalgias de um passado recente.

${ }^{67}$ ID., IB., pp.14-15. 
A revolução da Gabriela

\section{A tematização que não aconteceu: a emancipação da mulher}

Não é por acaso que a maioria dos artigos, críticas e reportagens sobre a Gabriela incide sobre as personagens femininas. São elas que interpretando papéis principais ou secundários suscitam o maior espanto e perplexidade nos públicos portugueses, num momento em que a cidadania feminina surgia consubstanciada na enorme participação das mulheres em todas as movimentações sociais, nos bairros, nas campanhas de alfabetização, na reforma agrária e nas empresas.

As imagens da mulher apresentadas nesta telenovela dão origem a uma discussão sobre a sensualidade exacerbada das mulheres nos trópicos - um tema recorrente na mitologia colonial e pós-colonial portuguesa - proporcionando, quer um espaço para novos valores e padróes estéticos, quer uma ruptura com os modelos/ estereótipos tradicionais da sexualidade e sensualidade das mulheres portuguesas. Gabriela, Glorinha, Malvina, Jerusa, Maria Machadão e as meninas do Bataclã apresentam, não só novos modelos estéticos de mulher (formas de valorizar e utilizar o corpo), como éticas de comportamento feminino, fundados na valorização das características físicas e intelectuais. Estes modelos tenderão a ser copiados, ou adaptados, pelas mulheres portuguesas, sobretudo pelas adolescentes $e$ jovens adultas contribuindo para a emergência de novos comportamentos de relacionamento intra e entre sexos, bem como novas formas de relacionamento entre as gerações. Por outro lado, as imagens femininas $e$ as tramas narrativas veiculadas na telenovela irão incentivar as mulheres portuguesas, sobretudo as jovens urbanas, a romperem com os modelos herdados da ditadura salazarista que via a mulher como sustentáculo do lar e garante da moral católica.

...É inacreditável! Sabe que vi pelo menos três Malvinas, com o mesmo cabelo e franja, me esperando? Achei lindo! 
...É por ser a primeira novela que vocês têm cá não?68 (Comentários de Elisabeth Savalla na entrevista a Maria João Avilez)

Nos inquéritos realizados pelos jornais estas imagens surgem em claro/escuro quando as mulheres inquiridas se pronunciam sobre as diferenças entre as lutas travadas na telenovela pela emancipação feminina e o que era, no momento, a realidade da mulher em Portugal. Comparam a liberdade de fumar, conduzir um carro, usar calças e namorar com a "escravatura" vivida pelas mulheres e meninas de Ilhéus (mesmo quando uma das inquiridas diz que não vê mais a Gabriela porque "o marido não vai em cantigas"). ${ }^{69}$ Uma outra inquirida, professora primária, introduzindo o tema da sexualidade, considera que a telenovela tem "efeitos negativos nas crianças porque na minha escola andam todos aos beijinhos, como o Nacib...".

Há época, a dimensão do fenómeno Gabriela na sociedade portuguesa já era perceptível, sendo que nas semanas finais da sua exibição, O Expresso, o semanário de maior circulação em Portugal, apela a "um estudo mais aprofundado sobre a questão que revelaria por portas-travessas muito do que gosta, imagina, sonha e projecta o português médio dos anos $70 "{ }^{70}$

\section{Algumas especulações ao jeito de conclusão}

Que conclusões retirar?

A primeira e, com certeza, definitiva conclusão é que a exibição da telenovela Gabriela, Cravo e Canela (e não é possível ignorar um outro programa contemporâneo, $A$ visita da Cornélia) alfabetizou o país num novo género e numa nova estética, após

${ }^{68}$ AvILEZ, Maria João. De Ilheús para Lisboa veio Malvina pela mão de Elisabeth. Expresso Revista, Lisboa, 12 de Novembro de 1977, p.8R.

${ }^{69}$ Inquérito: "Gabrielomania"... Op. cit., p.16.

${ }^{70} \mathrm{O}$ último episódio do mais popular programa apresentado em vinte anos de RTP. Expresso Revista, Lisboa, 12 de Novembro de 1977, p.14R. 
A revolução da Gabriela

quarenta anos de ditadura propagandística e dois anos de revolução manipuladora televisiva. Simultaneamente, inaugurou aquilo que alguns críticos, comentaristas e jornalistas designaram por "país televisivo"71 ou seja, o início, em Portugal, dos fenómenos inerentes à indústria cultural $e$ à massificação das audiências centrada na televisão.

Neste momento peculiar da história da televisão em Portugal assiste-se à tomada de consciência - principalmente por profissionais, críticos, comentaristas e intelectuais - da existência de uma indústria de conteúdos em português, altamente desenvolvida, portadora de lógicas próprias de criação $e$ divulgação, e do fascínio provocado nas audiências pelos seus produtos. Contudo, os indícios deste fenómeno coabitam, quer com uma imprensa estatizada e partidarizada, quer com os apelos à função de "serviço público de televisão", quer ainda com as denúncias de manipulação política desse mesmo serviço público. ${ }^{72}$

Por outro lado, o consenso colectivo vivenciado pela exibição da telenovela, coincide com grandes alterações estruturais designadas - unanimemente por historiadores, sociólogos e políticos - como de retorno à normalidade democrática. Coincide também, com o primeiro momento de liberalização económica, pós revolução 25 de Abril, decorrente das reprivatizações de grandes indústrias. As polémicas em torno da devolução de empresas $e$ indústrias aos seus anteriores proprietários, a aprovação da nova lei da reforma agrária e da imprensa, ou ainda, as polémicas em torno da entrada em Portugal da Pepsi e da Coca-Cola, simbolizam a resistência e a expectativa dos portugueses frente a uma nova sociedade $e$ a novos estilos de vida.

${ }^{71}$ Amorim, R. Gabriela desapareceu... Expresso Revista, Lisboa, 19 de Novembro de 1977, p.17R.

${ }^{72}$ LEITÃo, J. O uso do poder numa televisão a "trouxe-mouxe". Expresso Revista, Lisboa, 24 de Setembro de 1977, p.7R. 
Uma segunda conclusão refere-se ao papel determinante desempenhado pela indústria cultural e de conteúdos brasileira beneficiária de uma língua comum mas, também, dum imaginário comum, de mitos, heróis, acontecimentos, paisagens, recordações e saudades, facilmente, identificados por todos os portugueses. ${ }^{73}$

Convém referir que ao fenómeno telenovela em Portugal precede o sucesso da MPB que criou condições favoráveis à introdução de outros produtos media brasileiros, nomeadamente os programas de humor e a telenovela. No momento da exibição da Gabriela, a expansão da indústria cultural e de conteúdos brasileira é percebida como um factor de reforço da identidade, ao recuperar tanto elementos da história colonial (colonização e emigração portuguesa para o Brasil) como elementos da história recente de Portugal. A identificação com o produto telenovela dáse, portanto, num primeiro momento, através deste reconhecimento de imagens do Eu (Portugal) através de um Outro próximo (Brasil).

E aqui temos uma terceira conclusão: a alteração dos quotidianos provocada pela interpenetração abrupta entre a ficção $e$ a experimentação da realidade. Um primeiro indício de alteração é a adopção de novos ritmos domésticos pautados pelos horários de exibiçãa ${ }^{74}$; um outro indício é a interrelação entre novas propostas de consumo - como os refrigerantes Pepsi e Coca-Cola, os êxitos da trilha sonora ou tipo de penteados femininos - e a telenovela; ${ }^{75}$ um terceiro indício de alteração manifesta-se nos constrangimentos, nas surpresas ou nas expectativas perante a visualização de novas formas de

\footnotetext{
${ }^{73}$ FeATHERSTONE, M. O desmanche da cultura: globalização, pós-modernismo $e$ identidade. São Paulo, SESC, 1997, p.151.

${ }^{74}$ Há inúmeros artigos, comentários, notícias que focam a "ginástica" dos portugueses para conseguirem assistir à telenovela.

${ }^{75}$ Estas relações são detectáveis nas publicidades dos jornais.
} 
sensualidade e sexualidade ${ }^{76}$ Nesta perspectiva, Gabriela teve um papel importante ao dar a ver as relações de poder existentes não só entre as classes sociais como, no interior destas classes, entre homem/mulher, nomeadamente no casamento e na sexualidade.

Uma quarta conclusão de carácter especulativo - só possível de confirmar por meio de estudos mais aprofundados - é integrar o fenómeno de recepção da Gabriela, num primeiro momento de recepção da telenovela em Portugal caracterizado pelo deslumbramento ${ }^{77}$ e entendimento da telenovela como forma de ficção que ao dar a ver a realidade, educa e forma os públicos. Esta concepção vinculada à filosofia de "serviço público" da televisão evoluirá, rapidamente, para um segundo momento da recepção caracterizada pela feminização das audiências (muito estimulada pelas segundas exibições à hora do almoço) e fidelização dos públicos (anos 80/85). Um terceiro momento da recepção que se vislumbra é caracterizado pelo papel da telenovela brasileira como agente de globalização ${ }^{78}$ ao propor às classes médias portuguesas em ascensão - nos finais da década de 80 e sobretudo na década de $90 \mathrm{com}$ a privatização de canais de televisão comportamentos, estilos de vida e valores comuns às sociedades ocidentais modernas. No seguimento desta afirmação refere-se que a exibição, durante mais de vinte anos, de telenovelas brasileiras acompanhou os percursos de emancipação da mulher em Portugal, oferecendo-lhes novos modelos de comportamento, família e sexualidade, e propondo-lhes, em simultâneo, esclarecimentos úteis para a resolução de problemas afectivos e materiais do quotidiano. ${ }^{79}$

\footnotetext{
${ }^{76}$ São poucas e veladas as referências à sexualidade, mas há bastantes referências às manifestações de sensualidade $e$ aos constrangimentos que provocam.

${ }^{77}$ Ferin-CunHA, I. De como Portugal descobriu o Brasil: ou da novela da TV Globo em Portugal. Revista Arte, n 2, São Paulo, 1983, pp.15-17.

${ }^{78}$ Ferin-CunHA, I. As Agendas da telenovela... Op. cit., pp.579-587.

${ }^{79}$ ID. As telenovelas brasileiras em Portugal. Revista Trajectos, $n^{\circ} 3$, Lisboa, ISCTE, 2003.
} 
Isabel Ferin Cunha

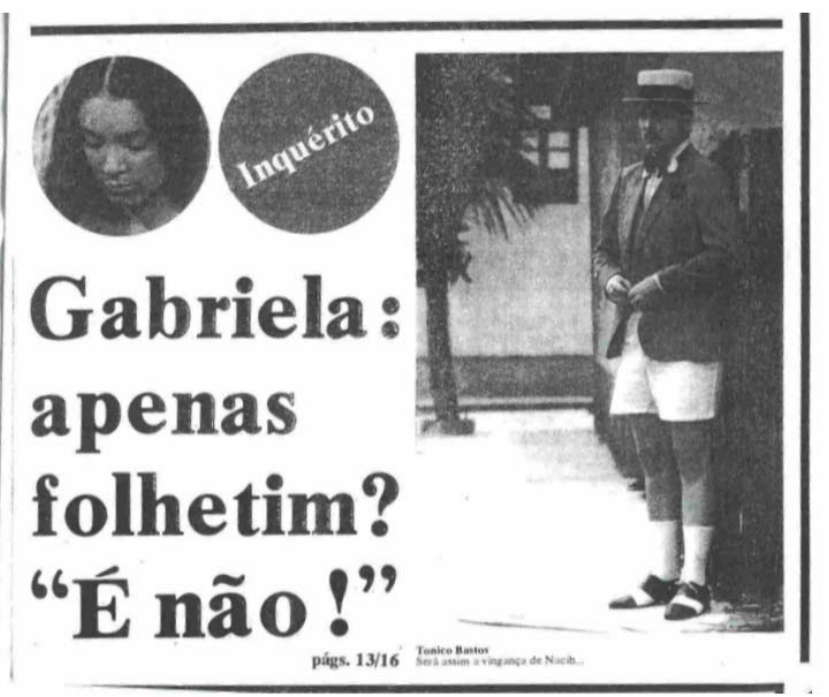

